\title{
Does Doxycycline work in synergy with cisplatin and oxaliplatin in colorectal cancer?
}

\author{
Jayesh Sagar*1,2, Kevin Sales ${ }^{1}$, Sas Dijk ${ }^{1}$, JanWillem Taanman ${ }^{3}$, \\ Alexander Seifalian ${ }^{2}$ and Mark Winslet ${ }^{1,2}$
}

\author{
Address: ${ }^{1}$ Division of Surgery and Interventional Science, University College London, Gower Street, London, WC1E 6BT, UK, ${ }^{2}$ Academic \\ Department of Surgery, Royal Free \& University College Medical School, Pond Street, London, NW3 2QG, UK and ${ }^{3}$ Department of Clinical \\ Neuroscience, Royal Free \& University College Medical School, Pond Street, London, NW3 2QG, UK \\ Email: Jayesh Sagar* - jsagar_2001@yahoo.com; Kevin Sales - k.sales@medsch.ucl.ac.uk; Sas Dijk - s.dijk@medsch.ucl.ac.uk; \\ JanWillem Taanman - j.taanman@medsch.ucl.ac.uk; Alexander Seifalian - a.seifalian@medsch.ucl.ac.uk; \\ Mark Winslet - m.winslet@mesch.ucl.ac.uk \\ * Corresponding author
}

Published: 6 January 2009

World Journal of Surgical Oncology 2009, 7:2 doi:10.1 186/1477-7819-7-2

This article is available from: http://www.wjso.com/content/7///2

(c) 2009 Sagar et al; licensee BioMed Central Ltd.

This is an Open Access article distributed under the terms of the Creative Commons Attribution License (http://creativecommons.org/licenses/by/2.0), which permits unrestricted use, distribution, and reproduction in any medium, provided the original work is properly cited.
Received: 16 May 2008

Accepted: 6 January 2009

\begin{abstract}
Background: In recent years, apart from antibacterial properties, doxycycline is reported to have cytotoxic and anti-proliferative actions in various cancers including colorectal cancer. Colorectal cancer constitutes one of the most common cancers in the western population. Apart from surgery, chemotherapy plays crucial role in the treatment of colorectal cancer. Cisplatin and oxaliplatin are most commonly used platinum compounds for the cancer chemotherapy. This study has looked for any impact of doxycycline on the cytotoxic effects of platinum compounds in colorectal cancer including its mechanisms of actions.
\end{abstract}

Methods: HT 29 colorectal cancer cells were used for this study. These cells were treated with cisplatin and oxaliplatin with or without doxycycline treatment. The caspase 3 gene expression was quantitated by gel electrophoresis and qualitated by real time polymerase chain reactions. The caspase 3 activity was assessed in HT 29 cells with fluorescence kit.

Results: The results revealed increased caspase 3 gene expressions and activities in HT 29 cells treated with cisplatin, oxaliplatin and doxycycline; however the combination of doxycycline with cisplatin and oxaliplatin did not report increased caspase 3 gene expressions and activity compared to cisplatin and oxaliplatin alone.

Conclusion: We concluded that doxycycline has role in apoptosis induction in the colorectal cancer. However, it did not show any synergy with platinum compounds in the colorectal cancer cells. This study also pointed towards possible caspase-independent actions of doxycycline with cisplatin and oxaliplatin. However, further work is required to underpin the mechanisms of actions of doxycycline. 


\section{Background}

Tetracyclines (TCNs) have been used in clinical practice as antibiotics in various bacterial, mycoplasma, chlamydiae, rickettsiae and protozoan infections since more than 5 decades [1]. Their main mechanism of action involves inhibition of protein synthesis by restricting binding of aminoacyl t-RNA to $30 \mathrm{~S}$ ribosomes [2]. Tetracyclines are believed to interfere the mitochondrial protein synthesis that let to the discovery of other effects, independent of their antimicrobial actions [3]. Recently, the renewed interest in the study of tetracyclines has evolved due to their ability to inhibit matrix metalloproteinase (MMPs) in various cancers such as prostate [4], melanoma [5], osteosarcoma [6], breast [7], leukaemia [8] and colorectal cancers [9]. Some of TCNs have been shown to work as apoptotic inducers [10]. Despite TCNs' emerging role as anti-invasive agents, their role in combination with other agents and the precise mechanisms are yet to be defined.

Apoptosis is the mechanism by which chemotherapeutic agents induce cancer cell death [11]. There are mainly two mechanisms/pathways of apoptosis, called intrinsic and extrinsic pathways. Caspases, the proteolyic enzymes, cysteine proteases, play essential role in execution of apoptosis [12]. Caspase 3 is one of the executioner caspases involved in both, the extrinsic and intrinsic pathways of apoptosis. Colorectal cancer is the third most common cancer in males and second most common cancer in females. It accounts for about 16,000 deaths per year in UK. Apart from surgery and radiotherapy, chemotherapy also plays significant role in the treatment of colorectal cancer. Cisplatin and oxaliplatin are two of most commonly used chemotherapeutic agents in the cancer chemotherapy of various cancers. However the problems of recurrence of disease and metastasis are not uncommon with these platinum compounds regimens. The advantages of doxycycline include long duration of actions and feasibility of oral administration. It has shown to inhibit cell proliferation and invasion and to induce apoptosis in colorectal cancer cell lines $[13,14]$. In this study we investigated whether doxycycline works in synergy with cisplatin and oxaliplatin or not in HT 29 colorectal cancer cell line.

\section{Methods \\ Cell line}

The human colorectal cancer cell line, HT 29 (purchased from ECACC) was used in experiments. The HT 29 cells were maintained in McCoy $5 \mathrm{~A}$ media supplemented with $10 \%$ fetal bovine serum, penicillin (50 units $/ \mathrm{ml})$ and streptomycin (50 units $/ \mathrm{ml}$ ) at $37^{\circ} \mathrm{C}$ in a humidified atmosphere with $95 \%$ air and $5 \% \mathrm{CO}_{2}$.

\section{Chemical reagents}

Cisplatin (Bristol-Myers Squibb, UK), oxaliplatin (SanofiSynthelabo, UK) and doxycycline (Alpharma, UK) were used in these experiments. $50 \mu \mathrm{M}$ of cisplatin and oxaliplatin were used $\left(\mathrm{LD}_{50}\right.$ obtained from our preliminary study). Doxycycline was used in $10 \mu \mathrm{g} / \mathrm{ml}$ dose (dose obtained from our preliminary data from the dose response study of doxycycline).

\section{Reverse transcription and polymerase chain reaction}

$2 \times 10^{4}$ cells/ml HT 29 cells were plated in 6 well plates for 24 hours for cellular attachments followed by treatment with $50 \mu \mathrm{M}$ of cisplatin or oxaliplatin with or without 10 $\mu \mathrm{g} / \mathrm{ml}$ of doxycycline. After 1, 4 and 24 hours of treatment the cells were trypsinized and cell pellets were used for RNA extraction with RNeasy minikit (Qiagen, UK) according to manufacturer's instructions. The extracted RNA was used for reverse transcription and polymerase chain reaction (RT-PCR) for GAPDH (as control) and caspase 3 gene expressions with One-Step RT-PCR kit (Qiagen, UK) according to manufacturer's instructions. The primers used are - GAPDH Forward - 5'-AACTTTGGCATTGTGGAAGG-3' Reverse 5'-GGAGACAACCTGGTCCTCAG-3' and Caspase-3 Forward -5'-TGTCATCTCGCTCTGGTACG3' Reverse -5'-AAATGACCCCTTCATCACCA-3'

The experiments were repeated three times. In all the experiments, doxycycline refers to the doxycycline treatment alone for 24 hours.

\section{Gel electrophoresis}

The RT-PCR products were resolved in 2\% agarose gel and electrophoresis was performed at $80 \mathrm{mV}$ and $400 \mathrm{~mA}$ for 60 minutes. The gel stained with ethidium bromide was visualised under ultraviolet light and band width was measured by Synogene software programme. The experiments were repeated for three times independently.

\section{Real time polymerase chain reaction}

The HT 29 cells were treated as per reverse transcription and the cells were trypsinized and cell pellets were used for RNA extraction with RNeasy minikit (Qiagen, UK) according to manufacturer's instructions. The caspase 3 and $\beta$ actin (as standard) genes expression was determined using two steps. The first step of reverse transcription was performed with the Omniscript RT Kit (Qiagen, UK) according to manufacturer's instructions and the real time PCR was performed with Roche Molecular Lightcycler, UK. The experiment was repeated three times independently.

\section{Caspase 3 activity}

$2 \times 10^{4}$ cells $/ \mathrm{ml}$ HT 29 cells were plated in 6 well plates for 24 hours for cellular attachments followed by treatment with $50 \mu \mathrm{M}$ of cisplatin or oxaliplatin with or without 10 
$\mu \mathrm{g} / \mathrm{ml}$ of doxycycline. After 1,4 and 24 hours of treatment, the cell pellets were collected through trypsinisation and caspase 3 activity was determined with Fluorometric Caspase 3 activity assay kit (R\&D Systems, UK) according to manufacturer's instructions. The experiment was repeated three times independently.

\section{Statistical analysis}

The $t$ test was performed with Microsoft Excel, Microsoft Office 2003 for statistical analysis on the Microsoft XP system. The $p$ value of $<0.05$ was considered as statistical significant.

\section{Results \\ RT PCR and gel electrophoresis}

The gel electrophoresis revealed presence of GAPDH amplicons in all the cell samples including control suggesting equal loading as an initial control (figure 1). It also showed increased caspase 3 transcripts in HT 29 cells treated with doxycycline compared to control $(\mathrm{p}=0.21)$. The caspase 3 transcripts level increased in time dependent manner in HT 29 cells treated with cisplatin and oxaliplatin alone. However its level decreased in time dependent manner in HT 29 cells treated with combinations of cisplatin or oxaliplatin and doxycycline ( $\mathrm{p}=$ 0.066 and $\mathrm{p}=0.001$ respectively) (figure 2 ).

\section{Real time PCR for Caspase 3 gene expression}

The two step real time PCR results revealed that the caspase 3 transcripts increased in the time dependent manner in the HT 29 colorectal cancer cells treated with cisplatin and oxaliplatin but caspase 3 transcripts levels decreased in the time dependent manner in the cells treated with cisplatin and oxaliplatin with doxycycline $(\mathrm{p}=0.01$ and $\mathrm{p}=$ 0.005) (figure 3 ).

\section{Caspase 3 activity}

Caspase 3 activity studies reported time dependent increase in the activity levels in HT 29 cells treated with cisplatin and oxaliplatin. Doxycycline also showed increased caspase 3 activity compared to control ( $\mathrm{p}=$ 0.034) (additional file 1). However, results did not reveal much increase in caspase 3 activity levels in cells treated with cisplatin and oxaliplatin in combination with doxycycline ( $\mathrm{p}=0.001$ and $\mathrm{p}=0.039$ respectively). These findings corresponded with the findings obtained in caspase 3 gene expressions.

\section{Discussion}

Colorectal cancer constitutes the third most common cancer and the second leading cause of cancer deaths in UK. About one in 20 men develops colorectal cancer in their lifetime (Cancer Research UK 2005, Cancer Stats). Apart from surgical intervention and radiotherapy, chemotherapy plays crucial role in the management of colorectal cancers. The main reasons for the mortality from colorectal cancers are metastases or recurrence of the disease. Recently, doxycycline has been reported to have cytotoxic and anti-proliferative actions on various cancer cells [3,4,14-18]; however, the exact mechanisms of apoptosis are not well understood. Doxycycline has also been reported to have anti-invasive properties in cancer cells[3,13]. To some extent, these effects of doxycycline may be co-related with its actions on mitochondria, where it induces reduction in protein synthesis through inhibitory effects on oxidative phosphorylation. However, the definite mechanisms of doxycycline are yet to be reported. According to literature, there has been only one study which looked into the combination effects of doxycycline with other agent [13]. This study answered whether doxycycline has any synergistic effects with other cytotoxic agents, the platinum compounds; cisplatin and oxaliplatin exploring the mechanisms of action on colorectal cancer cells at the same time.

Caspases are the cysteine proteases which are crucial for the process of apoptosis. Caspase 3 is one of the effector caspases in the apoptosis cascade. It is activated from procaspase 3 through intrinsic as well as extrinsic pathways and results in cell death. Increased caspase 3 gene expression or activity is considered as one of the hall mark of the apoptosis induction. We studied caspase 3 gene expression and activity levels to assess any synergic/additive impact of doxycycline on the effects of cisplatin and oxaliplatin. From the review of literature, it was concluded to use sub lethal dose of $10 \mu \mathrm{g} / \mathrm{ml}$ of doxycycline in these experiments, a level that has been reported in the gingival fluid following a systemic dose of doxycycline, and has been shown to arrest $G_{0} / G_{1}$ cell cycle in HT 29 cells. The caspase 3 gene expression revealed a time dependent increase of expression in the cells treated with cisplatin and oxaliplatin but there was time dependent decrease in caspase 3 transcripts in the cells treated with combination of drugs (figure 2) This difference was statistically significant in the HT 29 cells treated with oxaliplatin compared to combination of oxaliplatin and doxycycline (figure 2). These findings were confirmed by real time PCR studies which showed statistically significant difference in the caspase 3 gene expression in HT 29 cells treated with cisplatin or oxaliplatin in comparison with their combination treatment with doxycycline respectively (figure 3 ).

As mentioned earlier, Onoda et al were the only one who reported the impact of combination of doxycycline and cyclooxygenase-2 inhibitor in colorectal cancer cells [13]. Although they showed increased caspase 3 activity following doxycycline treatment, they did not study caspase 3 activity following the combination treatment of doxycycline and cyclooxygenase- 2 inhibitor. However, they reported inhibition of cell proliferation and attenuated 

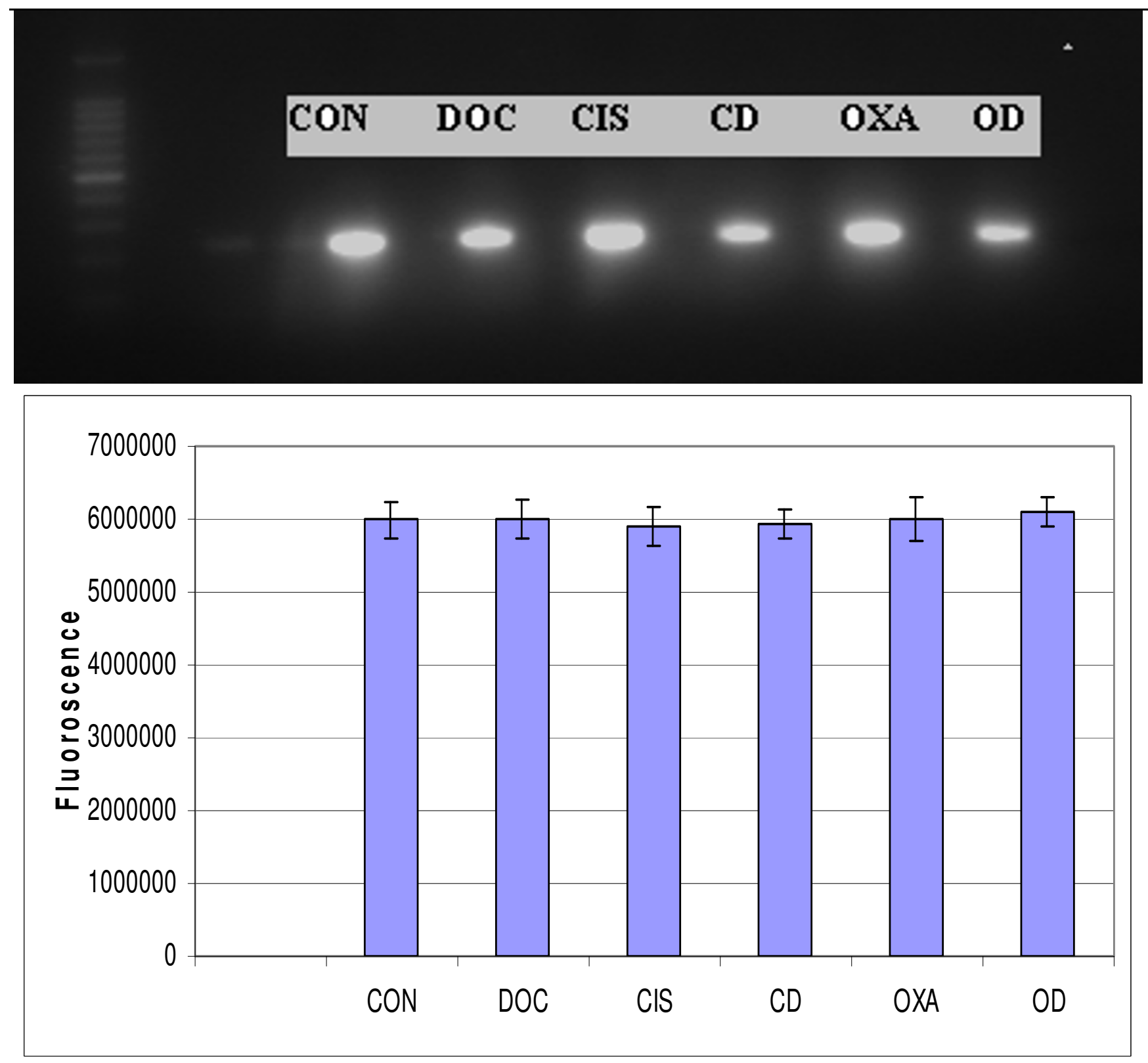

\section{Figure I}

Gel electrophoresis of GAPDH amplicons. The upper part reveals qualitative assessment of GAPDH gene expression while lower part shows quantitative assessment in different cell samples. $(C O N=$ Control, DOC $=$ Doxycycline, CIS $=$ Cisplatin, $C D=$ Cisplatin and Doxycycline, $\mathrm{OXA}=$ Oxaliplatin, $\mathrm{OD}=$ Oxaliplatin and Doxycycline). The data are depicted as means of three experiments \pm standard deviation.

matrix metalloproteinase expression following combination treatment. Our study showed similar results in the form of increased caspase 3 activity following doxycycline treatment in HT 29 cells, but showed decreased caspase 3 activity in cells treated with combination treatment. Therefore, to verify our findings, the caspase 3 activity assay was performed that reported statistically significant difference in the caspase 3 activity in HT 29 cells treated with cisplatin and oxaliplatin alone in comparison with combination of cisplatin/oxaliplatin and doxycycline (figure 4). Although the caspase activity was significantly low in the cells treated with combination therapy compared to 

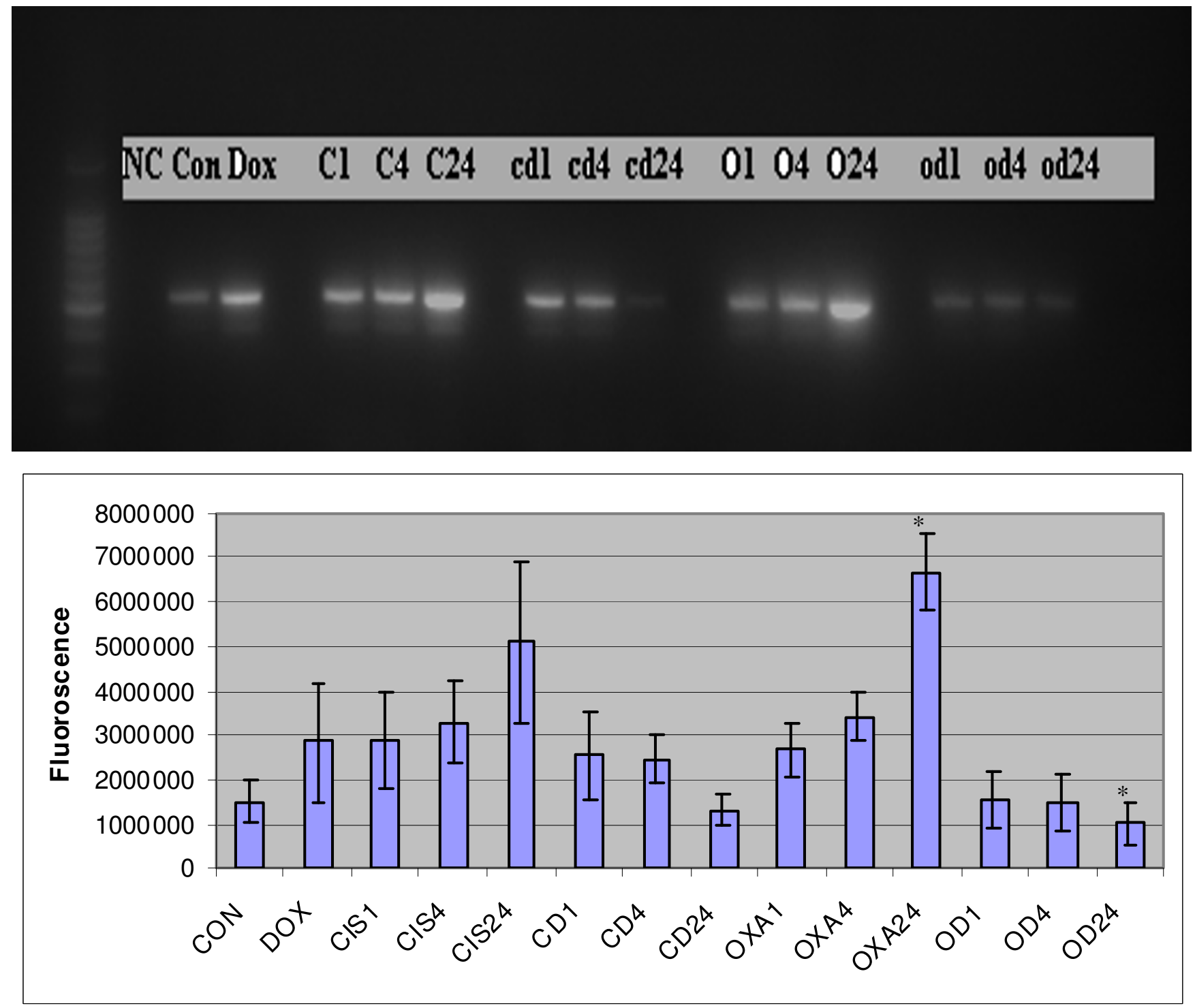

\section{Figure 2}

Gel electrophoresis of Caspase 3 RT PCR products in HT 29 cells treated with cisplatin or oxaliplatin with or without doxycycline. The upper part reveals qualitative assessment of caspase 3 gene expression while lower part shows quantitative assessment in different cell samples. $(\mathrm{NC}=$ Negative control, $\mathrm{Con}=\mathrm{CON}=$ Positive control, Dox $=\mathrm{DOX}=$ Doxycycline treatment for 24 hours, C(CIS) I; C4; C24 = Cisplatin treatment for I, 4 and 24 hours respectively, cd(CD) I; cd4; cd24 = Cisplatin and Doxycycline treatment for I, 4 and 24 hours respectively, O(OXA) I; O4; O24 = Oxaliplatin treatment for I, 4 and 24 hours respectively, od(OD) I; od4; 0d24 = Oxaliplatin and Doxycycline treatment for I, 4 and 24 hours respectively, $*$ - Statistically significant difference). The data are depicted as means of three experiments \pm standard deviation.

platinum compounds, doxycycline on its own showed statically significant caspase 3 activity compared to control (figure 4).

To clarify the impact of caspase 3 mediated apoptosis in the cytotoxic effects of doxycycline alone as well as in combination with platinum compounds, a general cell viability assay was considered appropriate. In our preliminary study, Alamar blue assay was used for cell viability study. This cytotoxicity assay revealed statistically no difference in the cytotoxicity of platinum compounds compared to the combination of doxycycline with platinum compounds (additional files 1 \&2). Thus combination of doxycycline with platinum compounds were reported to 


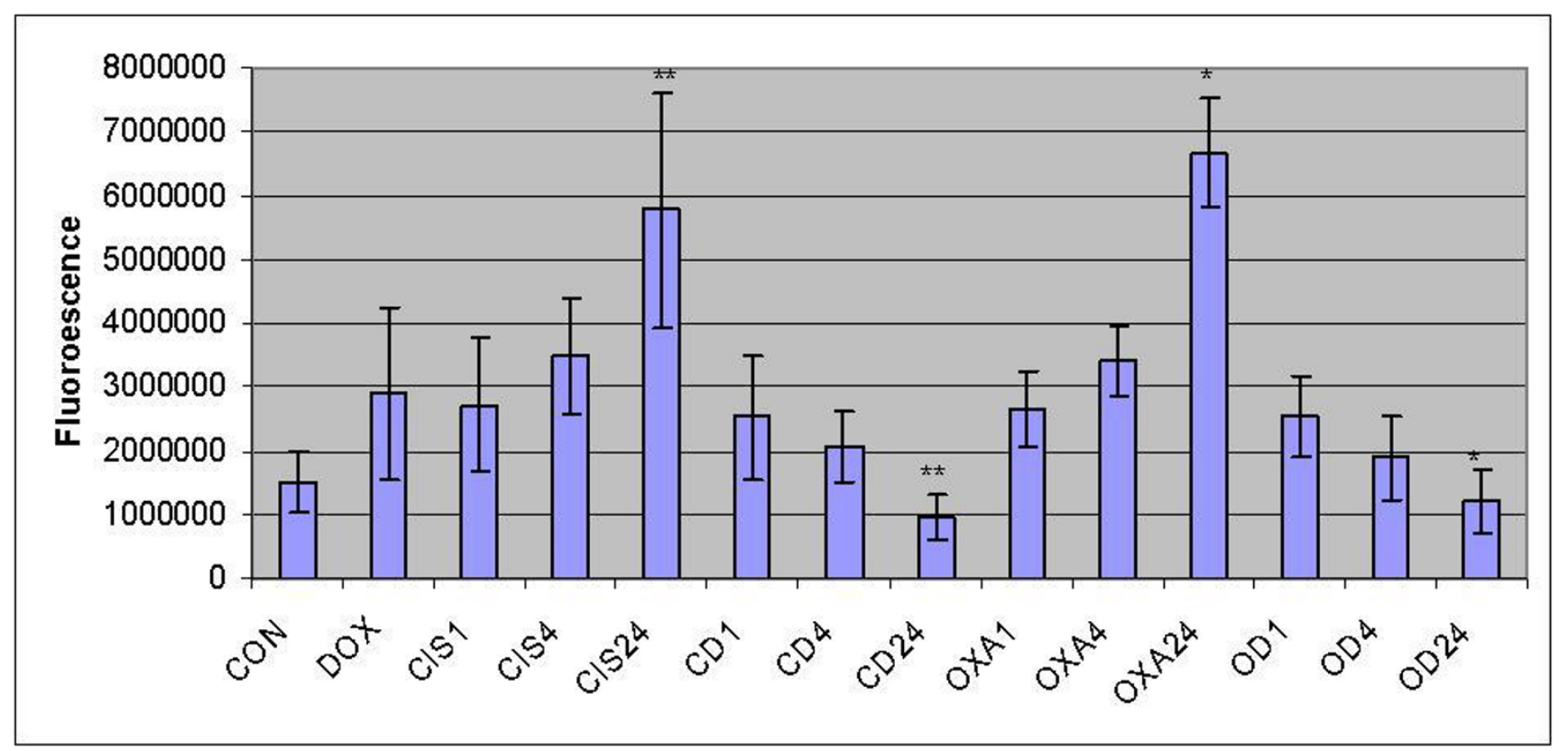

Figure 3

Quantitative presentation of the real-time PCR of caspase 3 gene expression in HT 29 cells. The HT 29 colorectal cancer cells were treated with cisplatin and oxaliplatin for 24 hours with or without doxycycline. The caspase 3 gene expression was measured in 2 steps; reverse transcription and real time PCR. (CON = Control, Dox $=$ DOX $=$ Doxycycline treatment for 24 hours, CISI; 4; 24 = Cisplatin treatment for I, 4 and 24 hours respectively, CD I; 4; $24=$ Cisplatin and Doxycycline treatment for I, 4 and 24 hours respectively, OXA I; 4; 24 = Oxaliplatin treatment for I, 4 and 24 hours respectively, OD I; 4; 24 = Oxaliplatin and Doxycycline treatment for I, 4 and 24 hours respectively, **, * - Statistically significant difference). The data are depicted as means of three experiments \pm standard deviation.

be no superior or synergistic to effects of platinum compounds in the colorectal cancer cells which contradict the findings of Onoda et al [13].

These findings have raised new questions about the role of doxycycline. It is possible that doxycycline may not have any synergistic actions with platinum compounds and may work on its own as cytotoxic, anti-proliferating or anti-invasive agent or doxycycline may have caspase-independent actions, especially in combination with platinum compounds. The advantages of doxycycline over other tetracyclines are its longer duration of action and comparatively less toxicity and thus may be considered as a potential candidate in future for cancer chemotherapy on its own or in combination with other agents, however to clarify the exact role of doxycycline alone as well as in combination with other agents and to underpin its mechanisms of actions, further study needs to be done.

The other key finding of this study was the similar findings obtained by caspase 3 gene expression and caspase 3 activity studies. We suggested similar efficacy of caspase 3 gene expression study and caspase 3 activity studies. The caspase 3 gene expression assay is expensive and more complex procedure compared to caspase 3 activity assays and thus we recommend the caspase 3 activity assay rather than caspase 3 gene expression study as cost effective procedure for future studies. We concluded that doxycycline may be useful as an apoptotic agent; however its role in combination with other chemotherapeutic agents needs to be clarified by further studies. These findings have opened the new avenues of further research.

\section{Conclusion}

We conclude that doxycycline has role in apoptosis induction in colorectal cancer cells, possibly via caspase 3 activation, however in combination with platinum compounds; it did not show any synergic or additive effects. This study also suggests possible role of caspaseindependent mechanisms of doxycycline when combined with platinum compounds. Further study needs to be carried out to outline the exact mechanisms of actions of doxycycline alone as well as in combination. We also recommend use of caspase 3 activity assay compared to more complex and more expensive caspase 3 gene expression study for caspase studies. 


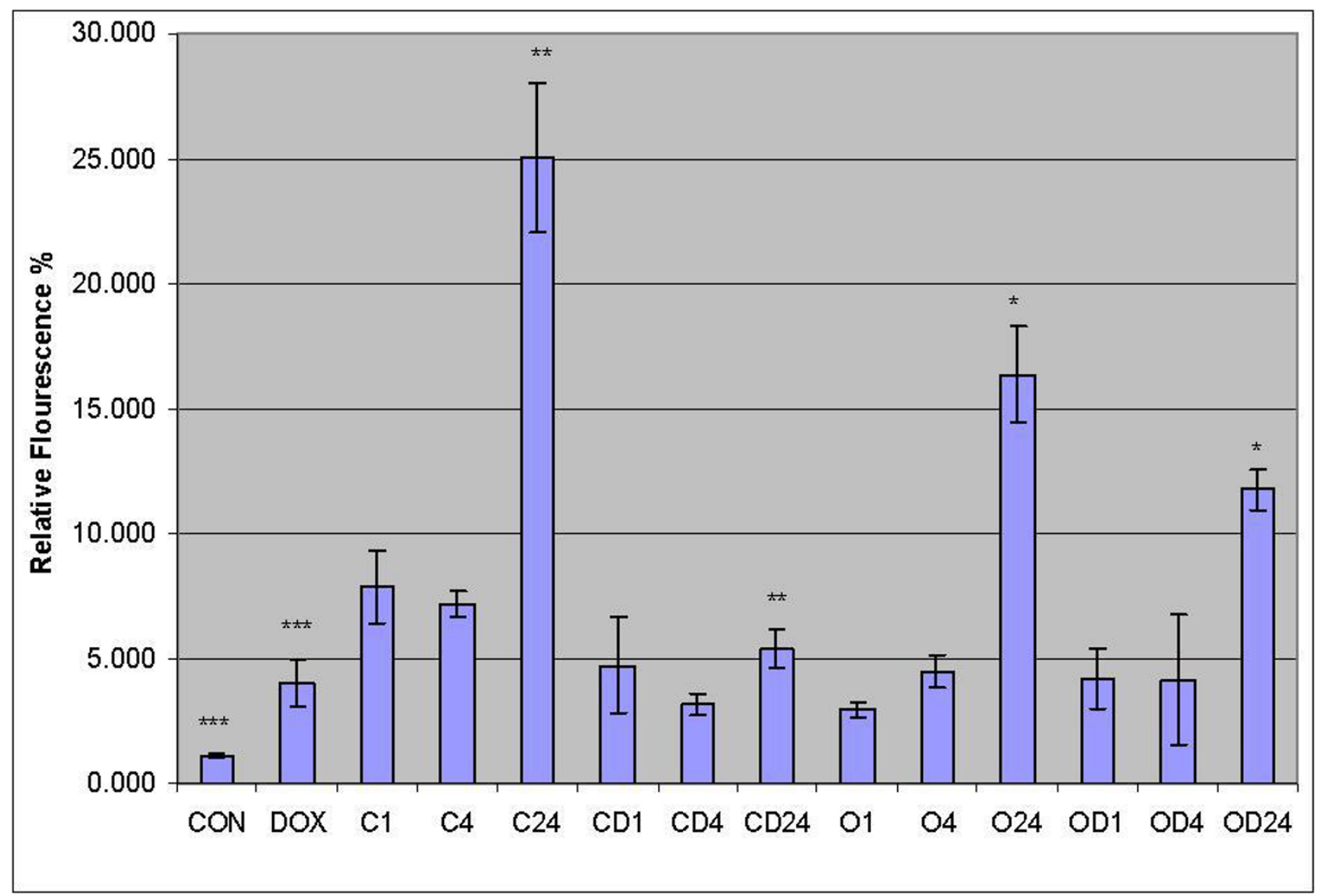

Figure 4

Quantitative presentation of caspase 3 activity in HT 29 cells. The HT 29 colorectal cancer cells were treated with cisplatin or oxaliplatin with or without doxycycline and caspase 3 activity was measured. (Con = CON = Positive control, Dox = DOX = Doxycycline treatment for 24 hours, CI; C4; C24 = Cisplatin treatment for I, 4 and 24 hours respectively, CDI; CD4; CD24 = Cisplatin and Doxycycline treatment for I, 4 and 24 hours respectively, O I; O4; O24 = Oxaliplatin treatment for I, 4 and 24 hours respectively, ODI; OD4; 0D24 = Oxaliplatin and Doxycycline treatment for I, 4 and 24 hours respectively. ${ }^{*}, * *, * * *$ Statically significant difference). The data are depicted as means of three experiments \pm standard deviation.

\section{Competing interests}

The authors declare that they have no competing interests.

\section{Authors' contributions}

JS was the main author and contributed in the all aspects of this work including preparation of manuscript. KS contributed in cell culture work. SD contributed in caspase gene expression studies. JWT contributed in caspase activity studies. MW contributed in the form of supervision and guidance and helped in preparation of manuscript. AS contributed to the preparation of the manuscript. All authors have read and agreed for the submission of this manuscript.

\section{Authors' note}

The methodology for Alamar blue assay has not been include in the methods section as it was part of the prelim- inary experiments, however if required please do not hesitate to contact the author.

\section{Additional material}

\section{Additional file 1}

Doxycyclin sup 1. Microsoft office file showing Cytotoxicity of cisplatin with or without doxycycline in HT 29 cells. The HT 29 cells were treated with different concentrations of cisplatin $(0-1000 \mathrm{M})$ with or without $10 \mu \mathrm{g} / \mathrm{ml}$ of doxycycline for 24 hours and the cytotoxicity assay was performed with Alamar blue assay according to the manufacturer's instructions.(- cisplatin, $\mathbf{\square}$ - cisplatin and doxycycline,). Data are depicted as means of three experiments \pm standard deviation. $(\mathrm{p}=0.84)$.

Click here for file

[http://www.biomedcentral.com/content/supplementary/14777819-7-2-S1.doc] 


\section{Additional file 2}

Doxycyclin sup 2. Microsoft office file showing Cytotoxicity of oxaliplatin with or without doxycycline in HT 29 cells. The HT 29 cells were treated with different concentrations of oxaliplatin $(0-1000 \mathrm{M})$ with or without $10 \mu \mathrm{g} / \mathrm{ml}$ of doxycycline for 24 hours and the cytotoxicity assay was performed with Alamar blue assay according to the manufacturer's instructions.(一 - oxaliplatin, $\mathbf{\square}$ - oxaliplatin and doxycycline, ). Data are depicted as means of three experiments \pm standard deviation. $(\mathrm{p}=0.95)$. Click here for file

[http://www.biomedcentral.com/content/supplementary/14777819-7-2-S2.doc]

\section{References}

I. Smilack JD: The tetracyclines. Mayo Clin Proc 1999, 74:727-729.

2. Clark JM Jr, Chang AY: Inhibitors of the transfer of amino acids from aminoacyl soluble ribonucleic acid to proteins. J Biol Chem 1965, 240:4734-4739.

3. Saikali Z, Singh G: Doxycycline and other tetracyclines in the treatment of bone metastasis. Anticancer Drugs 2003, 14:773-778.

4. Lokeshwar BL, Selzer MG, Zhu BQ, Block NL, Golub LM: Inhibition of cell proliferation, invasion, tumor growth and metastasis by an oral non-antimicrobial tetracycline analog (COL-3) in a metastatic prostate cancer model. Int J Cancer 2002, 98:297-309.

5. Seftor RE, Seftor EA, De Larco JE, Kleiner DE, Leferson J, Stetler-Stevenson WG, McNamara TF, Golub LM, Hendrix MJ: Chemically modified tetracyclines inhibit human melanoma cell invasion and metastasis. Clin Exp Metastasis 1998, 16:217-225.

6. Cakir $Y$, Hahn KA: Direct action by doxycycline against canine osteosarcoma cell proliferation and collagenase (MMP-I) activity in vitro. In Vivo 1999, 13:327-331.

7. Duivenvoorden WC, Popović SV, Lhoták S, Seidlitz E, Hirte HW, Tozer RG, Singh G: Doxycycline decreases tumor burden in a bone metastasis model of human breast cancer. Cancer Res 2002, 62:|1588-|159|.

8. Iwasaki H, Inoue H, Mitsuke Y, Badran A, Ikegaya S, Ueda T: Doxycycline induces apoptosis by way of caspase-3 activation with inhibition of matrix metalloproteinase in human T-lymphoblastic leukemia CCRF-CEM cells. J Lab Clin Med 2002, 140:382-386.

9. Gu Y, Lee HM, Roemer EJ, Musacchia L, Golub LM, Simon SR: Inhibition of tumor cell invasiveness by chemically modified tetracyclines. Curr Med Chem 200I, 8:26I-270.

10. D'Agostino P, Ferlazzo V, Milano S, La Rosa M, Di Bella G, Caruso R, Barbera C, Grimaudo S, Tolomeo M, Feo S, Cillari E: Chemically modified tetracyclines induce cytotoxic effects against $\mathrm{J74}$ tumour cell line by activating the apoptotic pathway. Int Immunopharmacol 2003, 3:63-73.

II. Schwartz LM, Smith SW, Jones ME, Osborne BA: Do all programmed cell deaths occur via apoptosis? Proc Natl Acad Sci USA 1993, 90:980-984.

12. Thornberry NA, Lazebnik Y: Caspases: enemies within. Science 1998, 281:1312-1316.

13. Onoda T, Ono T, Dhar DK, Yamanoi A, Fujii T, Nagasue N: Doxycycline inhibits cell proliferation and invasive potential: combination therapy with cyclooxygenase- 2 inhibitor in human colorectal cancer cells. J Lab Clin Med 2004, I 43:207-2 I6.

14. Onoda T, Ono T, Dhar DK, Yamanoi A, Nagasue N: Tetracycline analogues (doxycycline and COL-3) induce caspase-dependent and -independent apoptosis in human colon cancer cells. Int J Cancer 2006, I I 8:1309-1315.

15. Lokeshwar BL, Escatel E, Zhu B: Cytotoxic activity and inhibition of tumor cell invasion by derivatives of a chemically modified tetracycline CMT-3 (COL-3). Curr Med Chem 200I, 8:27I-279.

16. Mouratidis PX, Colston KW, Dalgleish AG: Doxycycline induces caspase-dependent apoptosis in human pancreatic cancer cells. Int J Cancer 2007, I 20:743-752.
17. Sourdeval M, Lemaire C, Brenner C, Boisvieux-Ulrich E, Marano F: Mechanisms of doxycycline-induced cytotoxicity on human bronchial epithelial cells. Front Biosci 2006, I I:3036-3048.

18. Wu J, Liu T, Xie J, Xin F, Guo L: Mitochondria and calpains mediate caspase-dependent apoptosis induced by doxycycline in HeLa cells. Cell Mol Life Sci 2006, 63:949-957.
Publish with Biomed Central and every scientist can read your work free of charge

"BioMed Central will be the most significant development for disseminating the results of biomedical research in our lifetime. "

Sir Paul Nurse, Cancer Research UK

Your research papers will be:

- available free of charge to the entire biomedical community

- peer reviewed and published immediately upon acceptance

- cited in PubMed and archived on PubMed Central

- yours - you keep the copyright
BioMedcentral 